\title{
Metacognition in addictive behaviors
}

\author{
Article for the Special Issue \\ Contemporary Perspectives on Cognition in Addictive Behaviors \\ Word count: 5,292 \\ (All sections included)
}

\author{
Marcantonio M. Spada \\ London South Bank University, London, UK \\ Gabriele Caselli \\ Studi Cognitivi, Cognitive Psychotherapy School, Modena, Italy \\ Ana V. Nikčević \\ Kingston University, Kingston upon Thames, UK \\ Adrian Wells \\ University of Manchester, Manchester, UK, \\ Manchester Mental Health and Social Care NHS Trust
}

\section{August 2014}

Revision 1

\begin{abstract}
Author Notes
Correspondence should be addressed to: Marcantonio M. Spada, Department of Psychology, School of Applied Science, London South Bank University, United Kingdom. Tel. +44 (0)20 7815 5760, e-mail: spadam@lsbu.ac.uk.
\end{abstract}




\begin{abstract}
Over the last twenty years metacognitive theory has provided a novel framework, in the form of the Self-Regulatory Executive Function (S-REF) model, for conceptualizing psychological distress (Wells \& Matthews, 1994; 1996). The S-REF model proposes that psychological distress persists because of unhelpful coping styles (e.g. extended thinking and thought suppression) which are activated and maintained as a result of metacognitive beliefs. This paper describes the S-REF model and its application to addictive behaviors using a triphasic metacognitive formulation. Evidence on the components of the triphasic metacognitive formulation is reviewed and the clinical implications for applying metacognitive therapy to addictive behaviors outlined.
\end{abstract}

(C) 2016, Elsevier. Licensed under the Creative Commons Attribution-NonCommercialNoDerivatives 4.0 International http://creativecommons.org/licenses/by-nc-nd/4.0/

Key words: addictive behaviors; cognitive-attentional syndrome; metacognition; metacognitive beliefs; metacognitive therapy; Self-Regulatory Executive Function model; triphasic metacognitive formulation of addictive behaviors 


\section{Metacognition in Psychopathology: The Self-Regulatory Executive Function Model}

The term 'metacognition', which is most often associated with the work of John Flavell (1979; 1987), can be broadly defined as knowledge and cognitive processes that are involved in the appraisal, control, or monitoring of thinking. Theory and research in metacognition emerged in developmental psychology and has, over the last forty years, been applied across various domains including aging, education, forensic psychology, memory, and neuropsychology (Dunlosky \& Metcalfe, 2009; Nelson \& Narens, 1990; Pintrich, 2000).

More recently, as a result of the work of Adrian Wells and his colleagues, metacognition has applied to conceptualizing and treating psychological distress. Wells and Matthews (1994; 1996) have proposed a multi-process model, the Self-Regulatory Executive Function (S-REF) model (presented in Figure 1), to represent dysfunctional cognition in psychological distress. The novel features of this model are: (1) the identification of a common or transdiagnostic set of processes and structures; (2) the modelling of cognition within an explicit cognitive architecture; (3) emphasis on top-down or strategic influences on processing bias; and (4) an explicit role assigned to metacognitive beliefs in the underpinning of coping styles that lead to psychological distress.

In Figure 1 the cognitive architecture of the S-REF model is represented as three interacting levels. The first level consists of a stimulus-driven processing network which operates outside conscious awareness and gives rise to products which intrude into consciousness. Examples of these products include affective (e.g. anxious feeling), cognitive (e.g. negative thoughts) and somatic (e.g. pain) intrusions. The second level consists of the S-REF, an online, voluntary and conscious processing system aimed at 
maintaining cognitive self-regulation in response to intrusions. The goal of S-REF processing is to reduce discrepancies between desired and current states of the self. Under adaptive conditions, S-REF activity is of short duration in that the individual selects coping styles that deal effectively with the discrepancy. However, in psychological distress the individual is unable to resolve the discrepancy due to unhelpful coping styles that lead to the perseveration of S-Ref activity. The initiation and cessation of S-REF activity is influenced by first level automatic processing (e.g. an intrusion related to body symptoms) and by the third level in the model: metacognitive knowledge. Metacognitive knowledge is conceptualised as information and beliefs about cognition that are positive and negative in content (e.g. "Worrying will help me cope" and "Some thoughts are dangerous") and generic plans for guiding cognition. Wells and Matthews (1994) argue that a particular thinking style is central to psychological disorder; the Cognitive Attentional Syndrome (CAS). The CAS consists of a variety of coping styles including extended thinking (e.g. desire thinking, rumination and worry), monitoring for threat, thought suppression and avoidance, that have paradoxical effects on self-regulation and discrepancy reduction. According to the S-REF model, the CAS is problematic because it causes negative thoughts and emotions to persist, leading to failures to modify dysfunctional metacognitive beliefs and stably resolve self-discrepancies.

The S-REF model emphasizes the importance of the processes which generate, monitor and maintain intrusive experiences, rather than focusing upon the content of such experiences (Wells, 2009). In psychological distress the selection and implementation of coping styles based on metacognitive beliefs focuses attention towards distress congruent information (e.g. environmental threats). This will typically establish a vicious cycle where 
a faulty blueprint (the CAS) is consistently applied to alleviate processes appraised as distressing but a successful resolution fails to be achieved. Over time the combination of applying the same blueprint leads to the development of an internal dissonance characterized by negative appraisals towards the selected coping styles and internal experiences more generally.

The S-REF model has led to the development of disorder-specific formulations and treatments for depression (Wells, 2009), generalized anxiety disorder (Wells, 1995), obsessive-compulsive disorder (Wells, 2000; Wells \& Matthews, 1994), post-traumatic stress disorder (Wells, 2000; Wells \& Sembi, 2004), and social anxiety disorder (Clark \& Wells, 1995). Metacognitive therapy (MCT), the psychological treatment based on the SREF model, has been evaluated across a series of studies for each of these disorders, with preliminary results indicating superior outcomes to cognitive behavioral therapy (Normann, van Emmerik \& Nexhmedin, 2014; Wells, 2013).

\section{Applying the S-REF Model to Addictive Behaviors}

Spada and Wells (2009) and Spada, Caselli \& Wells (2013) have applied the S-REF model to addictive behaviors (see Figure 2). In their formulation the CAS and metacognitive beliefs are conceptualised across three temporal phases of the addictive behavior episode: pre-enagagement, engagement, and post engagement. What follows is an exposition of these different phases in nicotine use.

In the pre-engagement phase triggers in the form of urges, images, memories or thoughts activate the S-REF and associated metacognitive beliefs to guide appraisal and coping style. Positive metacognitive beliefs such as "Thinking about having a cigarette will make me feel better" and negative metacognitive beliefs such as "I cannot control my 
thoughts of smoking” activate the perseverative processing of intrusions and attempts at their suppression (the CAS) leading to an escalation of negative affect and craving. As a consequence the smoker becomes more likely to use in order to regulate these feelings and escape the escalating discrepancy between current and desired state.

The activation of the pre-engagement phase requires awareness of a preference. It is important to note that if the addictive behavior becomes habitual then the pre-engagement phase may be bypassed. When habit has been established, the pre-engagement phase can occur in three circumstances: (1) in a relatively new contextual environment; (2) when the habitual addictive behavior is interrupted through external control; or (3) through conscious attempts to remain abstinent. This helps to explain why severely addicted individuals may not report pre-engagement extended thinking for example (Caselli \& Spada, 2011).

In the engagement phase positive metacognitive beliefs about engagement ("Smoking will help me control my thoughts/reduce my worrying”) are paralleled by changes in metacognitive monitoring (the ability to monitor internal states as a guide to knowing how close one is to resolving discrepancies and achieving the desired state). These two factors contribute to a reduced ability to regulate behavior. Specifically, reductions in metacognitive monitoring are thought to result from: (1) behaviors that distract from selfawareness and from monitoring the flow of goal-progress information thereby limiting the opportunity to identify a stop signal for engagement; and/or (2) the chemical effects of the addictive behavior (e.g. alcohol/nicotine) which affects higher order functioning and therefore impacts negatively on metacognitive monitoring.

Over the course of time and as the addictive behavior escalates in severity, negative metacognitive beliefs about its uncontrollability emerge, contributing to its perseveration. 
These include negative metacognitive beliefs about the power of thoughts about the addictive behavior causing uncontrollable engagement ("Thinking about smoking can make me do it”) and negative metacognitive beliefs about the uncontrollability of the addictive behavior once it is initiated (“Once I start smoking I find it difficult to stop”).

In the post-engagement phase, an intrusion (e.g. a self-blaming thought or withdrawal symptoms) leads to accessing positive metacognitive beliefs about postengagement rumination (e.g. "If I analyze why I am feeling this way I will understand why I smoke") and the activation of the associated coping styles of rumination and thought suppression. The latter lead to a worsening of negative affect increasing the likelihood of returning to engagement as a means of achieving self-regulation.

\section{A Review of Research Evidence on the Components of the Tripahsic Metacognitive} Formulation of Addictive Behaviors

The triphasic metacognitive formulation of addictive behaviors proposes that aspects of the CAS such as attentional bias, extended thinking (e.g. desire thinking, rumination and worry), disruption in metacognitive monitoring and thought suppression should be associated with addictive behaviors and lead to maladaptive consequences including increased levels of craving and engagement. The formulation also proposes that metacognitive beliefs should be associated with aspects of the CAS and addictive behaviors.

\subsection{Attentional Bias}

In the S-REF model attentional bias is a function of both automatic and strategic processes, however what is emphasised is the role of strategic processing. Consistent with this view the emotional Stroop effect appears to be more dependent on slow disengagement 
processes than on fast automatic bias (Phaf \& Kan, 2007) and on the voluntary maintenance of attention upon target-related cues (Field, Mogg, Zetterl \& Bradley, 2004). To this extent attentional bias is likely to be sensitive to the individual's coping styles which in turn are influenced by metacognitive beliefs and the motivation to continue or disengage from processing personally relevant stimuli. Thus, attentional bias is seen as a feature of the CAS: a manifestation of the individual's strategy to monitor for personally relevant cues and implement extended processing of them.

Attentional bias should therefore play a role in developing and maintaining: (1) addictive behavior; (2) risk of relapse; and (3) a strong and perseverative experience of craving (for a review see Field \& Cox, 2008). For example, among users of different substances, substance-related attentional bias is directly proportional to the quantity and frequency of the substance used (Field \& Cox, 2008). The association between attentional bias and substance use has been well-replicated for alcohol misuse (e.g. Sharma, Albery \& Cook, 2001; Field, Schoenmakers \& Wiers, 2008), cannabis use (Field, Eastwood, Bradley \& Mogg, 2006) and nicotine use (Mogg, Field \& Bradley, 2005). Longitudinal designs have also demonstrated the association between attentional bias and risk of subsequent relapse in alcohol abusers (Cox, Hogan, Kristian \& Race, 2002), tobacco smokers (Waters, Shiffman, Bradley \& Mogg, 2003), heroin users (Marissen, Franken, Waters, Blanken, van den Brink \& Hendriks, 2006) and cocaine users (Carpenter, Schreiber, Church \& McDowell, 2006).

\subsection{Extended Thinking}

Extended thinking refers to recurrent, dysfunctional and rigid thinking styles that perpetuate the accessibility of intrusions. Desire thinking, rumination and worry are the 
main types of extended thinking that have been identified in the literature. Desire thinking has been characterized as a voluntary process involving the elaboration of a desired target at a verbal level and imaginal level (Caselli \& Spada, 2010; Kavanagh, May, \& Andrade, 2009). The target of desire thinking may be an activity, an object, or a state (Kavanagh, Andrade, \& May, 2004, 2005). Rumination and worry are characterized by heightened selffocused attention involving persistent, recyclic, and predominantly verbal internal questioning about the causes, meaning, and consequences of one’s internal experiences. Rumination is focused on depressive symptoms and their consequences (Nolen-Hoeksema \& Morrow, 1991), while worry is characterized by an apprehensive expectation of possible negative outcomes in the future (Borkovec, 1994).

Research has shown that desire thinking occurs in nicotine dependence, problematic gambling and problem drinking (Caselli \& Spada, 2010). In addition desire thinking has been found to: (1) predict craving across a range of addictive behaviors (Caselli, Soliani \& Spada, 2013; Caselli \& Spada, 2011); (2) rise across the continuum of drinking and smoking behavior (Caselli, Ferla, Mezzaluna, Rovetto, Spada, 2012; Caselli, Nikčević, Fiore, Mezzaluna \& Spada, 2012); and (3) be associated with levels of problematic gambling (Fernie, Caselli, Giustina, Donato, Marcotriggiani \& Spada, 2014). On similar lines desire thinking has been found to discriminate between problematic and nonproblematic Internet users (Spada, Caselli, Slaifer, Nikčević \& Sassaroli, 2013). Research has also demonstrated that rumination is higher for problem drinkers compared to social drinkers (Caselli, Bortolai, Leoni, Rovetto, \& Spada, 2008), that it prospectively predicts alcohol use in community and clinical samples (Caselli, Ferretti, Leoni, Rebecchi, Rovetto \& Spada, 2010) and that it brings to increases in craving in experimental conditions 
(Caselli, Gemelli, Querci, Lugli, Canfora, Annovi, Rebecchi, Ruggiero, Sassaroli, Spada \& Watkins, 2013). Several studies have also supported the association between high levels of worry and the tendency to use alcohol in problem drinkers (Goldsmith, Tran, Smith, \& Howe, 2009; Smith \& Book, 2010).

\subsection{Thought Suppression}

Thought suppression is a mental control strategy involving the attempt to keep certain thoughts out of awareness. The engagement in thought suppression can lead to an increase in the suppressed thought (Wenzlaff \& Wegner, 2000). This paradoxical effect has been observed in individuals with addictive behaviors. For example, when alcohol dependent individuals try to suppress thoughts regarding alcohol, these thoughts may become hyper-accessible immediately afterward (Klein, 2007). In addition, alcohol dependent individuals that have been exposed to a suppression condition have been shown to be faster to endorse alcohol outcome expectancies following exposure to alcohol cues than individuals in a control group (Palfai, Monti, Colby \& Rohsenow, 1997). It also appears that both trait and state thought suppression contribute towards the depletion of neurocognitive resources needed to regulate urges (Garland, Carter, Ropes \& Howard, 2012). Finally, it has also been found that a greater use of smoking-related thought suppression in everyday life is significantly associated with a greater desire to smoke (Erskine, Ussher, Cropley, Elqindi, Zaman \& Corlett, 2012), attempts to quit smoking, and number of cigarettes smoked (Erskine, Georgiou \& Kvavilashvili, 2010). A similar association has also been observed between thought suppression and problem gambling (Riley, 2014). 


\subsection{Disruptions in Metacognitive Monitoring}

Metacognitive monitoring (the ability to monitor internal states as a guide to knowing how close one is to resolving discrepancies and achieving the desired state; Spada \& Wells, 2006; Spada, Zandvoort \& Wells, 2007) is likely to be affected by addictive substances. For example, Steele and Josephs (1990) have demonstrated that alcohol's pharmacological properties disrupt attentional processes (through the narrowing of perception to immediate cues and reduction of cognitive abstracting capacity), and Hull (1981) has shown that alcohol use reduces self-awareness (corresponding to the encoding of information in terms of self-relevance). Evidence also suggests that alcohol intoxication impairs neurological systems that underlie meta-level processing (Nelson, Graf, Dunlosky, Marlatt, Walker \& Luce, 1998). Furthermore research evidence has shown that not attending internally to the change in cognition and emotion (poor metacognitive monitoring) that occurs during alcohol and nicotine use is associated with excessive use (Spada \& Wells, 2006; Nikčević \& Spada, 2010). Finally, poor metacognitive monitoring has been associated to perserveration of gambling activity in individuals with gambling disorder (Spada, Giustina, Rolandi, Fernie \& Caselli, 2014).

\subsection{Metacognitive Beliefs}

Positive and negative metacognitive beliefs about engagement in addictive behaviors have been identified in nicotine dependence, gambling and problem drinking. Positive metacognitive beliefs relate to the effects of engaging in addictive behavior as a means of controlling and regulating cognition (e.g. "Smoking helps me to control my thoughts”) and affect (e.g. “Gambling will improve my mood”) (Nikčević \& Spada, 2010; Spada, Giustina, Rolandi, Fernie \& Caselli, 2014; Spada \& Wells, 2006, 2008; Toneatto, 
1999). Negative metacognitive beliefs concern the perception of lack of executive control over the engagement in the addictive behavior (e.g., "My smoking persists no matter how I try to control it"), uncontrollability of thoughts related to the addictive behavior ("The thought of gambling is stronger than my will”), thought-action fusion ("Thinking about using alcohol can make me drink"), and the negative impact of the engagement in the addictive behavior on cognitive functioning ("Drinking will damage my mind”) (Hoyer, Hacker, \& Lindenmeyer, 2007; Nikčević \& Spada, 2010; Spada, Giustina, Rolandi, Fernie \& Caselli, 2014; Spada \& Wells, 2006, 2008; Toneatto, 1999). Positive and negative metacognitive beliefs about alcohol use have been found to predict the severity of alcohol use in binge drinking university students (Clark, Tran, Weiss, Caselli, Nikčević \& Spada, 2012), problem drinking in clinical and non-clinical samples (Spada \& Wells, 2009, 2010) and drinking behaviour independently of alcohol outcome expectancies in non-clinical samples (Spada, Moneta, \& Wells, 2007).

Positive and negative metacognitive beliefs have also been found to play a role in desire thinking. Positive metacognitive beliefs about desire thinking ("Imagining something I desire gives me control over my choices”) relate to the use of desire thinking as a form of coping with cognitive-affective triggers present in addictive behaviour (Caselli \& Spada, 2010; 2013). Negative metacognitive beliefs about desire thinking (“I cannot stop thinking about a desire activity") concern the uncontrollability of desire thinking and its negative impact on executive control over behavior, self-image, and cognitive performance (Caselli \& Spada, 2010; 2013).

Research has also shown that general negative metacognitive beliefs are elevated across addictive behaviours including alcohol (Spada, Caselli, \& Wells, 2009; Spada \& 
Wells, 2005; Spada, Zandvoort \& Wells, 2007), gambling (Lindberg, Fernie \& Spada, 2011), nicotine (Nikčević \& Spada, 2008; Spada, Nikčević, Moneta \& Wells, 2007) and Internet use (Spada, Langston, Nikčević \& Moneta, 2008). These studies have tended to show that negative metacognitive beliefs about the need to control thoughts and lack of cognitive confidence positively predict addictive behavior.

\section{Clinical Implications of a Triphasic Metacognitive Formulation of Addictive}

\section{Behaviors}

The triphasic metacognitive formulation of addictive behaviors presented implies that MCT (Wells, 2000, 2009) may be applied to addictive behaviors. For example, in the pre-engagement phase the primary therapeutic target would be interrupting extended thinking and modifying associated metacognitive beliefs. In this phase Detached Mindfulness, which involves encouraging the patient to observe their urge, images, memories and thoughts without trying to control or change them, would feature prominently as would the use of techniques aimed at the postponement of extended thinking.

In the engagement phase the primary focus would be on attention modification (in particular the enhancement of metacognitive monitoring) and the modification of positive and negative metacognitive beliefs about engagement in addictive behavior. In this phase Situational Attentional Refocusing (SAR; Wells 2000), which aims to increase the flow of adaptive information in awareness so the individual is better able to regulate cognition and behavior, could be employed. This technique would require the patient to purposefully direct their attention onto cues related to the addictive behavior, such as quantity of cigarettes smoked and proximity to desired goals, with the objective of enhancing 
metacognitive monitoring/awareness during engagement and help identify an adaptive stop signal.

Finally, in the post-engagement phase a direct modification of rumination related to the addictive behavior and the modification of associated metacognitive beliefs would be indicated. In this phase similar techniques to those used in the pre-engagement phase would be employed to interrupt post-engagement rumination.

The extent to which MCT would focus on a particular phase would depend on the severity and duration of the addictive behavior presentation together with the individual's level of awareness and treatment goals. For example, the pre-engagement phase would feature more prominently in: (1) occasional and irregular engagement; (2) the early stages of engagement when this is aimed at coping with negative affect; and (3) attempts to remain abstinent following protracted engagement. For those presenting with an entrenched or regular addictive behavior the engagement phase would be the primary focus of formulation and treatment. Finally, the post-engagement phase would be of central importance when there is a chronic and persistent presentation with a history of relapses combined with awareness of the addictive behavior.

\section{Conclusions}

The S-REF model provides a conceptual framework for expressing how stored knowledge and beliefs about thinking processes influence the choice of plans and regulation of coping. A review of the research evidence indicates that central features of the S-REF model; CAS configurations and metacognitive beliefs, are present in addictive behavior. These processes can be interpreted within a triphasic metacognitive formulation that has implications for adapting and targeting MCT for addictive behaviors. MCT has 
demonstrated efficacy in emotional disorders (Normann, van Emmerik \& Nexhmedin, 2014) and the current analysis leads to the hypothesis that it will be efficacious in treating addictive behaviors. Future work using this treatment framework in addictive behaviors should lead to refinements in the key treatment components.

The empirical data is consistent with a triphasic metacognitive formulation of addictive behaviours but the data remains limited. In particular, research investigating the link between metacognitive beliefs and both attentional bias and actual addictive behaviour is needed. Research should also focus on broadening the understanding of the relationship between metacognition and implicit processing (e.g. Moss \& Albery, 2009), testing the role of changes in putative maintenance and causal mechanisms (e.g. extended thinking, metacognitive monitoring) as moderators of change, and evaluating the efficacy of MCT in the treatment of addictive behaviours. 


\section{References}

Borkovec, T. D. (1994). The nature, functions and origins of worry. In G. C. L. Davey \& F. Tallis, (Eds), Worrying: Perspectives on Theory, Assessment and Treatment (pp. 533). New York, USA: Wiley.

Carpenter, K. M., Schreiber, E., Church, S. \& McDowell, D. (2006). Drug stroop performance: relationships with primary substance of abuse and treatment outcome in a drug-dependent outpatient sample. Addictive Behaviors, 31, 174-181.

Caselli, G., Bortolai, C., Leoni, M., Rovetto, F. \& Spada, M. M. (2008). Rumination in problem drinkers. Addiction Research \& Theory, 16, 564-571.

Caselli, G., Ferla, M., Mezzaluna, C., Rovetto, F. \& Spada, M. M. (2012). Desire thinking across the continuum of drinking behaviour. European European Addiction Research, 18, 64-69.

Caselli, G., Ferretti, C., Leoni, M., Rebecchi, D., Rovetto, F. \& Spada, M. M. (2010). Rumination as a predictor of drinking behaviour: a prospective study. Addiction, 105, 1041-1048.

Caselli, G., Gemelli, A., Querci, S., Lugli, A. M., Canfora, F., Annovi, C., Rebecchi, D., Ruggiero, G. M., Sassaroli, S., Spada, M. M. \& Watkins, E. R. (2013). The effect of rumination on craving across the continuum of drinking behaviour. Addictive Behaviors, 38, 2879-2883.

Caselli, G., Nikčević, A. V., Fiore, F., Mezzaluna, C. \& Spada, M. M. (2012). Desire thinking across the continuum of nicotine dependence. Addiction Research \& Theory, 20, 382-388. 
Caselli, G., Soliani, M. \& Spada, M. M. (2013). The effect of desire thinking on craving: an experimental investigation. Psychology of Addictive Behaviors, 27, 301-306.

Caselli, G. \& Spada, M. M. (2010). Metacognitions in desire thinking: a preliminary investigation. Behavioural and Cognitive Psychotherapy, 38, 629-637.

Caselli, G. \& Spada, M. M. (2011). The Desire Thinking Questionnaire: Development and psychometric properties. Addictive Behaviors, 36, 1061-1067.

Caselli, G. \& Spada, M. M. (2013). The Metacognitions about Desire Thinking Questionnaire: Development and psychometric properties. Journal of Clinical Psychology, 69, 1284-1298.

Clark, A., Tran, C., Weiss, A., Caselli, G., Nikčević, A. V., \& Spada, M. M. (2012). The Big 5 facets of personality and metacognitions as predictors of level of alcohol consumption in binge drinking university students. Addictive Behaviors, 37, 537540.

Clark, D. M., \& Wells, A. (1995). A cognitive model of social phobia. In R. Heimber, M. Liebowitz, D. A. Hope, \& F. R. Schneier (Eds.), Social Phobia: Diagnosis, Assessment, and Treatment. New York: Guilford Press.

Cox,W. M., Hogan, L. M., Kristian, M. R. \& Race, J. H. (2002). Alcohol attentional bias as a predictor of alcohol abusers’ treatment outcome. Drug and Alcohol Dependence, 68, 237-243.

Dunlosky, J. \& Metcalfe, J. (2009). Metacognition. London, UK; Sage Publications.

Erskine, J. A., Georgiou, G. J. \& Kvavilashvili, L. (2010). I suppress, therefore I smoke: effects of thought suppression on smoking behavior. Psychological Sciences, 21, 1225-1230. 
Erskine, J. A., Ussher, M., Cropley, M., Elqindi, A., Zman, M. \& Corlett, B. (2012). Effect of thought suppression on desire to smoke and tobacco withdrawal symptoms. Psychopharmacology, 219, 205-2011.

Fernie, B. A., Caselli, G., Giustina, L., Donato, G., Marcotriggiani, A. \& Spada, M. M. (2014). Desire thinking as a predictor of gambling. Addictive Behaviors, 39, 793796.

Field, M. \& Cox, W. M. (2008). Attentional bias in addictive behaviors: A review of its development, causes and consequences. Drug and Alcohol Dependence, 97, 1-20.

Field, M., Eastwood, B., Bradley, B. P. \& Mogg, K. (2006). Selective processing of cannabis cues in regular cannabis users. Drug and Alcohol Dependence. 85, 75-82.

Field, M., Mogg, K., Zetteler, J. \& Bradley, B. P. (2004). Attentional biases for alcohol cues in heavy and light social drinkers: the roles of initial orienting and maintained attention. Psychopharmacology, 176, 88-93.

Field, M., Schoenmakers, T. \& Wiers, R. W. (2008). Cognitive processes in alcohol binges: a review and research agenda. Current Drug Abuse Reviews, 1, 263-279.

Flavell, J. H. (1979). Metacognition and cognitive monitoring: A new area of cognitivedevelopmental inquiry. American Psychologist, 34, 906-911.

Flavell, J. H. (1987). Speculations about the nature and development of metacognition. In F. E. Weinert \& R. H. Kluwe (Eds.), Metacognition, Motivation and Understanding (pp. 21-29). Hillside, New Jersey: Lawrence Erlbaum Associates.

Garland, E. L., Carter, K., Ropes, K. \& Howard, M. O. (2012). Thought suppression, impaired regulation of urges, and addiction-Stroop predict affect-modulated cuereactivity among alcohol dependent adults. Biological Psychology, 89, 87-93. 
Goldsmith, A. A., Tran, G. Q., Smith, J. P., \& Howe, S. R. (2009). Alcohol expectancies and drinking motives in college drinkers: Mediating effect on the relationship between generalized anxiety and heavy drinking in negative-affect situations. Addictive Behaviors, 34, 505-13.

Hoyer, J., Hacker, J., \& Lindenmeyer, J. (2007). Metacognition in alcohol abusers: How are alcohol-related intrusions appraised? Cognitive Therapy and Research, 31, 817-831.

Hull, J. G. (1981). A self-awareness model of the causes and effects of alcohol assumption. Journal of Abnormal Psychology, 90, 586-600.

Kavanagh, D. J., Andrade, J., \& May, J. (2004). Beating the urge: Implications of research into substance-related desires. Addictive Behaviors, 29, 1399-1372.

Kavanagh, D. J., Andrade, J., \& May, J. (2005). Imaginary relish and exquisite torture: The elaborated intrusion theory of desire. Psychological Review, 112, 446-467.

Kavanagh, D. J., May, J., \& Andrade, J. (2009). Tests of the elaborated intrusion theory of craving and desire: Features of alcohol craving during treatment for an alcohol disorder. British Journal of Clinical Psychology, 48, 241-254.

Klein, A.A. (2007). Suppression-induced hyperaccessibility of thoughts in abstinent alcoholics: A preliminary investigation. Behaviour Research and Therapy, 45, 169177.

Lindberg, A., Fernie, B. A. \& Spada, M. M. (2011). Metacognitions in problem gambling. Journal of Gambling Studies, 27, 73-81.

Marissen, M. A. E., Franken, I. H. A., Waters, A. J., Blanken, P., van den Brink, W. \& Hendriks, V. M. (2006). Attentional bias predicts heroin relapse following treatment. Addiction 101, 1306-1312. 
Mogg, K., Field, M. \& Bradley, B. P. (2005). Attentional and approach biases for smoking cues in smokers: an investigation of competing theoretical views of addiction. Psychopharmacology, 180, 333-341.

Moss, A. C. \& Albery, I. P. (2009). A dual-process model of the alcohol-behavior link for social drinking. Psychological Bulletin, 135, 516-530.

Nelson, T. O., Graf, A., Dunlosky, J., Marlatt, A., Walker, D. \& Luce, K. (1998). Effect of acute alcohol intoxication on recall and on judgments of learning during the acquisition of new information. In: G. Mazzoni \& T. O. Neslon (Eds). Metacognition and Cognitive Neuropsychology, Monitoring and Control Processes. LEA: Mahwah, NJ. pp 161-180.

Nelson, T. O., \& Narens, L. (1990). Metamemory: A theoretical framework and some new findings. In G. H. Bower (Ed.), The Psychology of Learning and Motivation. New York, USA: Academic Press.

Nikčević, A. V. \& Spada, M. M. (2008). Metacognitions across the continuum of smoking dependence. Behavioural and Cognitive Psychotherapy, 36, 333-339.

Nikčević, A. V. \& Spada, M. M. (2010). Metacognitions about smoking: a preliminary investigation. Clinical Psychology \& Psychotherapy, 17, 536-542.

Nolen-Hoeksema, S., \& Morrow, J. (1991). A prospective study of depression and posttraumatic stress symptoms after a natural disaster: The 1989 Loma Prieta earthquake. Journal of Personality and Social Psychology, 61, 115-121.

Normann, N., van Emmerik, A. P. \& Nexhmedin, M. (2014). The efficacy of metacognitive therapy for anxiety and depression: A meta-analytic review. Depression and Anxiety, 31, 402-411. 
Palfai, T. P., Monti, P. M., Colby, S. M. \& Rosenow, D. J. (1997). Effects of suppressing the urge to drink on the accessibility of alcohol outcome expectancies. Behaviour Research and Therapy, 35, 59-65.

Phaf, R. H. \& Kan, K. J. (2007). The automaticity of emotional stroop: a meta-analysis. Behaviour Therapy and Experimental Psychiatry , 38, 184-199.

Pintrich, P. R. (2000). The role of goal orientation in self-regulated learning. In M. Boekaerts, P. R. Pintrich \& M. Zeidner (Eds.), Handbook of Self-Regulation (pp. 451-502). New York, USA: Academic Press.

Sharma, D., Albery, I. P. \& Cook, C. (2001). Selective attentional bias to alcohol related stimuli in problem drinkers and non-problem drinkers. Addiction, 96, 285-295.

Smith, J. P. \& Book, S. W. (2010). Comorbidity of generalized anxiety disorder and alcohol use disorders among individuals seeking outclient substance abuse treatment. Addictive Behaviors, 35, 42-45.

Spada, M. M., Caselli, G., Slaifer, M., Nikčević, A. V. \& Sassaroli, S. (2013). Desire thinking as a predictor of problematic Internet use. Social Science Computer Review, published electronically $24^{\text {th }}$ November.

Spada, M. M., Caselli, G. \& Wells, A. (2009). Metacognitions as a predictor of drinking status and level of alcohol use following CBT in problem drinkers: a prospective study. Behaviour Research and Therapy, 47, 882-886.

Spada, M. M., Caselli, G. \& Wells, A. (2013). A triphasic metacognitive formulation of problem drinking. Clinical Psychology \& Psychotherapy, 20, 494-500. 
Spada, M. M., Giustina, L., Rolandi, S., Fernie, B. A. \& Caselli, G. (2014). Profiling metacognition in gambling disorder. Behavioural and Cognitive Psychotherapy, published electronically $15^{\text {th }}$ April.

Spada, M. M., Langston, B., Nikčević, A. V. \& Moneta, G. B. (2008). The role of metacognitions in problematic internet use. Computers in Human Behavior, 24, $2325-2335$.

Spada, M. M., Moneta, G. B. \& Wells, A. (2007). The relative contribution of metacognitive beliefs and expectancies to drinking behaviour. Alcohol and Alcoholism, 42, 567-574.

Spada, M. M., Nikčević, A. V., Moneta, G. B. \& Wells, A. (2007). Metacognition as a mediator of the relationship between emotion and smoking dependence. Addictive Behaviors, 32, 2120-2129.

Spada, M. M. \& Wells, A. (2005). Metacognitions, emotion and alcohol use. Clinical Psychology \& Psychotherapy, 12, 150-155.

Spada, M. M. \& Wells, A. (2006). Metacognitions about alcohol use in problem drinkers. Clinical Psychology \& Psychotherapy, 13, 138-143.

Spada, M. M. \& Wells, A. (2008). Metacognitive beliefs about alcohol use: development and validation of two self-report scales. Addictive Behaviors, 33, 515-527.

Spada, M. M. \& Wells, A. (2009). A metacognitive model of problem drinking. Clinical Psychology \& Psychotherapy, 16, 383-393.

Spada, M. M. \& Wells, A. (2010). Metacognitions across the continuum of drinking behaviour. Personality and Individual Differences, 49, 425-429. 
Spada, M. M., Zandvoort, M. \& Wells, A. (2007). Metacognitions in problem drinkers. Cognitive Therapy and Research, 31, 709-716.

Steele, C. M. \& Josephs, R. A. (1990). Alcohol myopia, its prized and dangerous effects. American Psychologist, 45, 921-933.

Toneatto, T. (1999). A metacognitive analysis of craving: Implications for treatment. Journal of Clinical Psychology, 55, 527-537.

Waters, A. J., Shiffman, S., Bradley, B. P. \& Mogg, K. (2003). Attentional shifts to smoking cues in smokers. Addiction 98, 1409-1417.

Wells, A. (1995). Worry and the incubation of intrusive images following stress. Behaviour Research and Therapy, 33, 579-583.

Wells, A. (2000). Emotional Disorders \& Metacognition: Innovative Cognitive Therapy. Chichester, UK: Wiley.

Wells, A. (2009). Metacognitive Therapy for Anxiety and Depression. New York, USA: Guilford Press.

Wells, A. (2013). Advances in Metacognitive Therapy. International Journal of Cognitive Therapy, 6, 186-201.

Wells, A., \& Matthews, G. (1994). Attention and emotion: A clinical perspective. Hove, UK: Lawrence Erlbaum Associates.

Wells, A., \& Matthews, G. (1996). Modelling cognition in emotional disorder: The S-REF model. Behaviour Research and Therapy, 34, 881-888.

Wells, A., \& Sembi, S. (2004). Metacognitive therapy for PTSD: A preliminary investigation of a new brief treatment. Journal of Behavior Therapy and Experimental Psychiatry, 35, 207-318. 
Wenzlaff, R. M. \& Wegner, D. M. (2000). Thought suppression. Annual Review of Psychology, 51, 59-91. 
Figure 1: The S-REF model of psychological disorder

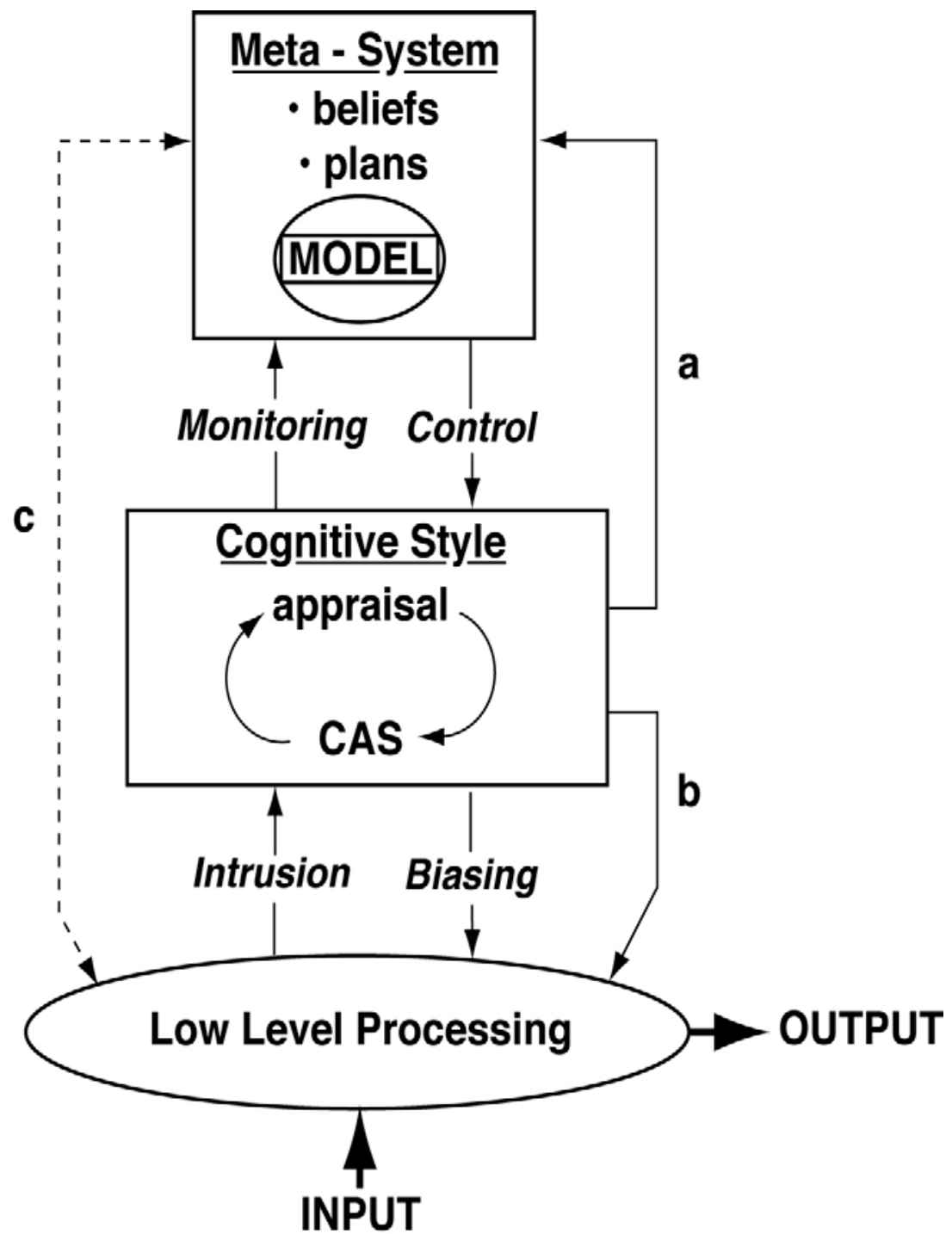

From Wells (2009, p.9). Copyright 2009 by The Guilford Press. Reprinted by permission. 


\section{Figure 2: A triphasic formulation of the S-REF model in addictive behaviors}

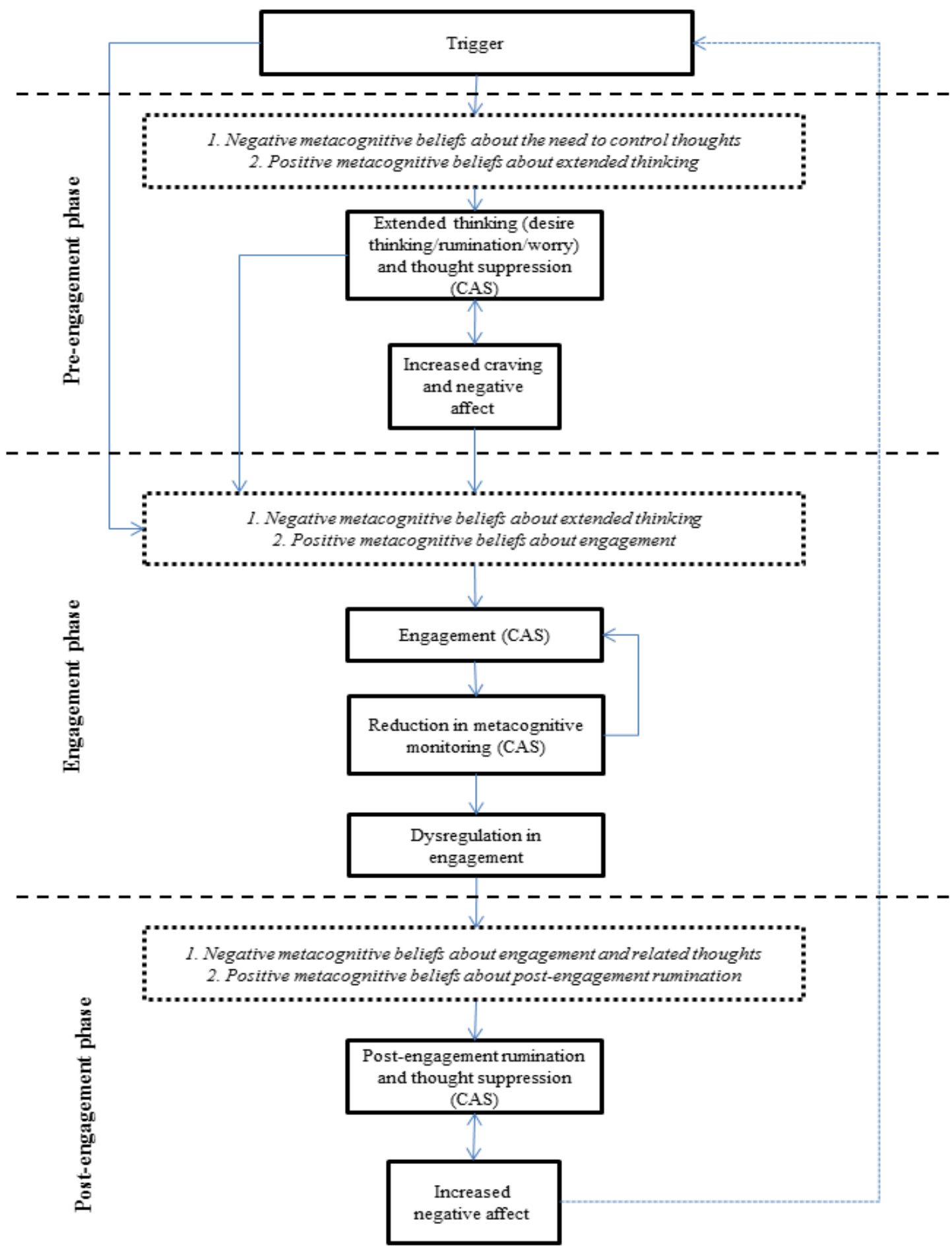

Adapted from Spada, Caselli \& Wells (2013). 